\title{
QUALIDADE DE VIDA NO TRABALHO E MOTIVACÃO PARA SERVIDORES EM ABONO PERMANÊNCIA PERSISTIREM NA ATIVA
}

Carlos Augusto Cunha Filho; Programa de Pós-Graduação em Gerontologia da Universidade Federal de Santa Maria-RS; E-mail: cac.filho@hotmail.com; Miriam Cabrera Corvelo Delboni; Programa de Pós-Graduação em Gerontologia da Universidade Federal de Santa Maria; E-mail: miriamdelboni@gmail.com;

Patrícia Chagas; Programa de Pós-Graduação em Gerontologia da Universidade Federal de Santa Maria; E-mail: profpatriciachagas@gmail.com

\section{RESUMO}

Introdução: $\mathrm{O}$ abono permanência constitui importante fator de desoneração da previdência pública, pois contribui para a manutenção de servidores na ativa, principalmente daqueles que se encontram na plenitude da carreira, com conhecimento e experiência acumuladas. Entretanto pouco se sabe por que estes servidores permanecem na ativa, mesmo estando aptos à aposentadoria. Objetivo: Identificar a qualidade de vida no trabalho e as motivações dos servidores em abono permanência para persistirem na atividade. Métodos: Estudo transversal, com 135 servidores em abono permanência de uma instituição federal de ensino (IFE). Os dados foram coletados através de questionário estruturado, contendo informações sociodemográficas e questões sobre a qualidade de vida no trabalho e motivações para permanência na IFE. Resultados: A idade média da amostra foi de $59 \pm 4,42 \mathrm{anos}$, com predominância do sexo feminino $(58,5 \%)$, casados $(62,2 \%)$ e com dois filhos (36,3\%). A predominância foi de doutores $(31,1 \%)$ e a jornada de trabalho de 40 horas semanais $(48,1 \%)$. Para as condições de qualidade de vida no trabalho, as manifestações foram de satisfação (58,5\%), exceto em relação aos benefícios, com o que se mostraram insatisfeitos $(41,4 \%)$. As principais motivações para a permanência em atividade foram o gosto pelo trabalho e pela atividade desenvolvida (38,5\%), seguido da possibilidade de ganhos financeiros $(28,1 \%)$ e do sentimento de pertencimento à instituição $(9,6 \%)$. Conclusão:Os servidores em abono permanência da amostra mostraram-se satisfeitos com sua qualidade de vida no trabalho, com exceção dos benefícios recebidos. E a sua principal motivação para a postergação da aposentadoria é o gosto pelo trabalho da atividade desenvolvida.

Palavras-chave: Abono permanência; Aposentadoria; Envelhecimento

Agradecimento: O presente trabalho foi realizado com apoio da Coordenação de Aperfeiçoamento de Pessoal de Nível Superior - Brasil (CAPES) 